\title{
Analysis of the Partnership for Health Promotion at School in Bulgaria
}

\author{
Stela Ludmilova Georgieva ${ }^{1}$ \\ Medical University
}

\author{
Mariela Stefanova Kamburova ${ }^{2}$ \\ Medical University
}

\author{
Manolya $\mathrm{Un}^{3}$ \\ Medical University
}

\begin{abstract}
According to the concept of health promotion, health is a shared responsibility of individuals, the community, the state, and non-governmental organizations. Partnership offers great potential for addressing problems and achieving goals, but it is also associated with certain difficulties. Establishing a successful partnership requires common purpose, shared responsibilities, complementary competencies, collaboration, and mutual respect. The aim of this paper is to analyze whether partnership as a main principle of health promotion has been put into practice in the observed school community. A comprehensive medico-social survey on school health promotion was conducted from September 2012 to May 2013 over a representative sample of schools in the Pleven region of Bulgaria. Data were collected through a self-administered questionnaire among 1,280 members of the school community, interviews with school principals, and a review of the documents. Questions are directed toward the elements of the coordinated school health model. Data analysis of the presented part of the study, which examined the partnership for health promotion at school, was consistent with the methodology of the partnerships analysis tool using a specially designed checklist for evaluation. Over $90 \%$ of the investigated subjects and organizations realize the necessity of partnership. They have a clear goal to improve the well-being of the school community and a shared understanding that the benefits from partnership outweigh the exertions and costs. On the other hand, not all potential partners are included in the process of planning priorities for action. Almost half do not always have a clear idea about their responsibilities for fulfilling the goals. Both the positive and weak points of the partnership were able to be considered. The necessity for partnerships in promoting school health is recognized but difficult to transform into real action due to limited competencies and collaborations.
\end{abstract}

\section{Keywords}

School health promotion $\bullet$ Coordinated school health model $\bullet$ Partnership for health promotion

\footnotetext{
1 Correspondence to: Stela Ludmilova Georgieva (MD, PhD), Department of Public Health Sciences, Faculty of Public Health, Medical University, Pleven, Bulgaria. Email: georgieva_sl@yahoo.com

2 Department of Public Health Sciences, Faculty of Public Health, Medical University, Pleven, Bulgaria. Email: mariela_kamburova@yahoo.com

3 Faculty of Medicine, Medical University, Pleven, Bulgaria. Email: manolyaun@gmail.com

Citation: Georgieva, S. L., Kamburova, M. S., \& Un, M. (2017). Analysis of the partnership for health promotion at school
} in Bulgaria. Sanitas Magisterium, 3, 37-46. http://dx.doi.org/10.12738/SM.2017.1.0026 
Health is formed and experienced by people within the settings of their everyday life: where they learn, work, play, and live (World Health Organization [WHO], 1986). According to the concept of health promotion, health is a shared responsibility of individuals, the community, the state, non-governmental organizations, and more working together to achieve common health goals (Dooris, 2006). Effective health improvements call for partnership because health is a complex category that includes physical, mental, and social dimensions. The desired public health outcomes might be attained if professions and partners could just communicate well (Barr, Koppel, Reeves, Hammick, \& Freeth, 2008).

Schools have been identified as a key setting for health promotion. The concept of a health promoting school is one of the most effective approaches for public health improvement. It extends beyond the formal health education curriculum and includes considering schools' physical and social environments. It also emphasizes that the partnership between all members of a wide school community (school staff, families, professional and non-governmental organizations, etc.) be recognized as an important precondition for improving the health and well-being of individuals and communities (Denman, 1999). A multi-partner community approach shows potential for improving health in elementary and secondary school children. It contributes to better outcomes from interventions against unhealthy eating and obesity (Tucker et al, 2011), for mental health improvement (Ramey \& Rose-Krasno, 2015; Shah, 2011), and so on. Cooperation is essential for experiencing health promotion in schools and other settings, which may seem obvious, but can be elusive and difficult to sustain (Young, Buijs, \& Josiute, 2014). Involving parents, school staff, and students in common activities is often difficult to make happen.

Parental engagement. Parental engagement in school is defined as the "common work and efforts of parents and school staff to support and improve the learning, development, and health of children and adolescents." There is considerable evidence that students who feel supported by their parents are less likely to experience emotional distress, consider/attempt suicide, drop out of school and education, or eat unhealthily. In addition, school efforts to promote health among students have been shown to be more successful when parents are involved. Interventions with a parental-engagement component are usually beneficial at increasing positive health behaviors (i.e., children's school-related physical activity) or at decreasing the likelihood of their children starting smoking (Centers for Disease Control and Prevention [CDC], 2012).

Staff contribution. The role of school staff for health promotion and education is undisputed. School staff including the school principal, teachers, school nurses, social workers, and so on contributes toward students' acquiring healthy behaviors. They are potential role models for students, and all of them contribute to students' 
effective and cognitive development. The teacher, as a responsible professional, can play an active role in participatory approaches in various ways. He can have more of the students be involved in health projects; provide support, insight, and knowledge; facilitate learning processes, and so forth. (Jensen \& Simovska, 2005). All teachers need to understand their potential contribution to students' attitudes and beliefs in terms of health and affective development, not just with the bounds of their own subject (Jourdan, Samdal, Diagne, \& Carvolho, 2008). Their mission is not to implement class-based curriculum but to operate in a number of areas, including developing appropriate school-health policies, enhancing the social environment, and linking with relevant community agencies (Didier, McNamara, Simar, Geary, \& Pommier, 2010).

Student participation. The concept of student participation is currently popular in health promoting schools. It should be carefully defined because of the possibility of manifesting different types of student involvement. In health promotion, token participation is characterized by focusing on prescribed knowledge and closed/ convergent outcomes, as well as targeting individuals isolated from the surrounding environment. In contrast, genuine participation stresses students' own knowledge construction and open/divergent outcomes, as well as targeting individuals within their own context. Genuine participation is in accordance with a democratic health promoting school aimed at students' empowerment and competence of action (Jensen \& Simovska, 2005). Potvin (2007) defined student participation as practices that involve collaboration between students and various groups of actors concerning health-related issues in order to influence decision-making regarding the designing, planning, implementation, or evaluation of health promotion measures (Griebler \& Novak, 2012; Griebler, Rojatz, Simovska, \& Forster, 2014; Hamdan, Story, French, Fulkerson, \&, Nelson, 2005). Involving adolescents in different projects is related to building health skills and the capacity for action towards health: preparing a production, planning an event, or impacting the community (Larson \& Angus, 2011). Youth participation refers to the active engagement and real influence of youths, not their passive presence or token roles in adult agencies. The quality of participation is measured not only by its scope, such as $x$ number of people attending $y$ number of activities, but also by its quality, such as when people have a real effect on the process, influence a particular decision, or produce a favorable outcome. The issue is not necessarily whether the effort is youth-led, adult-led, or intergenerational, but whether people have had some effect (Checkoway, 2011).

Working in partnership unconditionally offers greater potential to address problems and achieve goals, but it is also associated with certain difficulties and challenges. Establishing a successful partnership requires a common vision of problems and ways of coping with them, a common purpose, a perceived need to work 
together to achieve an objective, shared duties and responsibilities, complementary competencies, better collaboration, and mutual respect. Effective partnership relies on clear communication and a shared understanding of who is responsible for what (Whole Child Education, 2009).

\section{Purpose}

This paper aims to analyze whether partnership as a main health promotion principle has been put into practice in the observed school community.

\section{Method}

\section{Time and Place of the Study}

A comprehensive medico-social study on health promotion at school was conducted from September 2012 to May 2013 over a representative sample of schools in the region of Pleven, Bulgaria.

\section{Data Collection}

Data were collected through a self-administered questionnaire among 1280 subjects under study including different groups of the school community (students, parents, and staff) to examine issues from different viewpoints. Interviews with school principals and a review of school documentation were also conducted. A specially designed tool was used comprised of a panel of questions for assessing the physical characteristics of the school environment, school health education, students' mental and emotional wellbeing at school, partnership for health promotion, and more.

\section{Data Analysis}

Data analysis and interpretation were consistent with the concept of the health promoting school. Processing the statistical data was carried out using Microsoft Office Excel 2010 and SPSS 13.0 for Windows.

For partnership analysis, the methodology of the partnership analysis tool, created by Victorian Health Promotion Foundation (2011) and adopted to the current study, was used. A checklist that defines key features of a successful partnership for health promotion also was used. It is organized into five areas as follows: determining the need for the partnership, making sure partnerships work, planning collaborative action, implementing collaborative actions, and minimizing the barriers to partnership. Different criteria for partnership were scored from 0 (complete disagreement with the statement made) to 4 (full agreement). Lacking a strong opinion (I don't know, I can't estimate) was evaluated with two points. To complete the checklist, different approaches can be applied: 
i. The leading organization (in this case, the school) can fill in the checklist and present the results to a meeting of the partnership stakeholders (as used in this study).

ii. Each party can be given a copy to complete independently, then compare and discuss the results at a meeting. This approach ensures the views of every partner are given equal weight.

iii. Representatives of the various parties in the partnership fill the checklist jointly. This approach will tend to emphasize consensus among members.

Results are evaluated as follows:

i. Scores under $50 \%$ of the possible maximum result in the idea of partnership as not being well recognized; it must be strictly reviewed.

ii. Scores between $50-85 \%$ signal that the partnership is in the right direction of activity but must pay more attention to some of its components to be truly effective.

iii. Scores higher than $85 \%$ find a genuine partnership, and efforts should be directed towards preserving and consolidating the achieved results.

\section{Results}

Belief in the benefits of promotion activities for improving health was expressed by all of the study participants. However, some differences of opinion on the existence of an effective partnership between family and school were found.

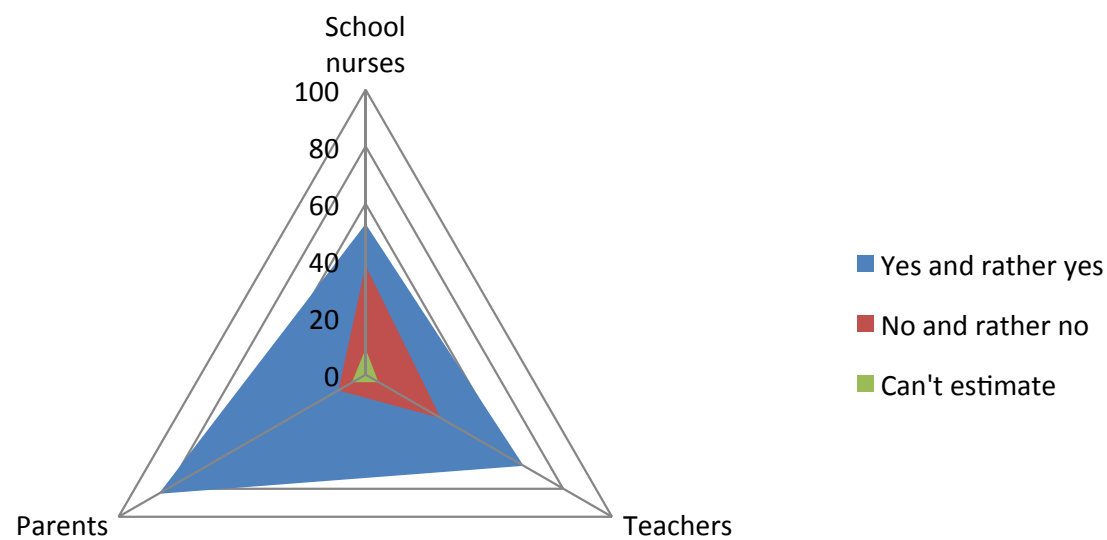

Figure 1. Satisfaction of parents and staff about the partnership between family and school towards health promotion. 
Greater consistency in the views was expressed in terms of public control over adolescent behavior. As shown in Figure 2, the three groups that were compared agree with the statement that public control of risk behaviors is insufficient and ineffective, their answers almost completely overlapping.

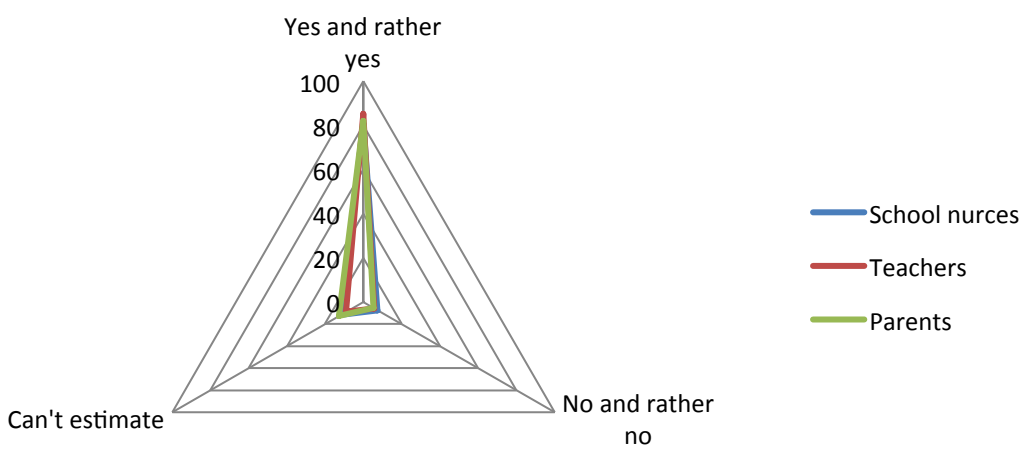

Figure 2. Agreement of the respondents with the statement that public control on adolescent's behavior is insufficient and ineffective.

Study results show that two-thirds of families express agreement about participating in health promotion activities organized in school, but $90 \%$ of them have never been invited to participate. Moreover, they don't know whether their children are involved in such activities.

According to student opinion, health promotion and education activities are conducted in school. Students define their role in the health education process as a "passive audience."

In our study, the first approach has been used to complete the questionnaire and assess the partnership based on an interview with school principals. Sixty-seven percent of results fall into the second category of accepted rating scale, as presented in Table 1. 
Table 1

Check-list for Partnership Evaluation

Check-list for Partnership Evaluation

$\begin{array}{lllll}4 & 3 & 2 & 1 & 0\end{array}$

Determining the need for the partnership

- There is a clear goal for the partnership.

- There is a perceived need for the partnership in terms of areas of common interests + and complementary capacity.

- The partners are willing to share some of their ideas, resources, influence, and power to fulfill the goal.

- The perceived benefits of the partnership outweigh the perceived costs.

Making sure partnership work

- The managers in each organization (or division) support the partnership.

- Partners have the necessity skills for collaborative action.

- There are strategies for partnership-skills enhancement by increasing workforce competencies.

- The administrative, communication, and decision-making structure of the partnership is as simple as possible.

Planning collaborative action

- All partners are involved in planning and setting priorities for collaborative action.

- The lines of communication, roles, and expectations of partners are clear.

\section{$+$}

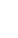

$\begin{array}{lllllll} & 4 & 3 & 2 & 1 & 0\end{array}$

Implementing collaborative action

- There are investments of time, personnel, materials, or facilities in the partnership.

- There are regular opportunities for informal and voluntary contact between staff from the different agencies and other members of the partnership.

Minimizing the barriers to partnerships

- There is a core group of skilled and committed (in terms of the partnership) staff that + has continued over the life of the partnership.

- There are formal structures for sharing information and resolving boundary disputes. +

Source: Victorian Health Promotion Foundation (2008). The partnership analysis too.

\section{Discussion}

Notably, established relationships satisfied mainly parents while almost a half of the school staff did not express such certainty (Fig. 1). This could probably be explained by higher staff competencies in health promotion and higher expectations on the established partnership between the school and family, respectively. At the same time, the school does not take active actions to improve this partnership.

To increase parent engagement in school health, schools must positively connect with parents. Schools should also provide a variety of activities and frequent opportunities to fully engage parents. Schools can sustain parental engagement by addressing the common challenges of getting and keeping parents engaged (CDC, 2012).

A number of studies that reported better cognitive effect referred to increased knowledge, skills, and health-related competencies as a result of students' participation in school health promotion. Student participation as a passive audience (tokenistic participation) in the process of school health education is not very effective at improving health knowledge or building positive attitudes towards health and healthy lifestyles. A systematic review of the effect of student participation in school 
health promotion endorses an understanding that distinguishes between the qualities of tokenistic and genuine participation. Genuine student participation is defined as having influence over decisions and activities in the school health promotion processes, rather than simply taking part in them (Simovska, 2007). According to this conceptualization, simple forms of student participation such as answering questions and taking part in activities are not considered participation.

Other authors reported students' positive, motivating feelings concerning the participatory processes and a sense of ownership related to their own efforts at production. Effects related to individual self-perception are an increase in selfconfidence, self-esteem, and self-efficacy. Positive influences on students' perspectives include students' attitudes and problem-solving orientation. Their attention is focused on personal and social resources, as well as the potential for health promotion, rather than deficits and difficulties. Students also recognize participation and collaboration as important values (Gribler et al, 2014).

\section{Conclusions}

i. Partnership is an important mechanism for building the capacity of health promotion using different but complementary resources.

ii. The necessity for a partnership between school, family, and society in the direction of health promotion is recognized by all members of the school community, but some difficulties are encountered putting it into practice, such as not all partners are involved in planning and setting priorities for collaborative action; the administrative, communication, and decision-making structure of the partnership is not as simple as can be, and other.

iii. School staff, represented by teachers and school nurses, is not satisfied with school-family collaboration. However, they have not taken steps toward improving collaboration.

iv. The school should increase its activity for improving collaborations with family for health-promotion activities.

v. Token student participation in health promotion is popular (rather than genuine) participation, which decreases the effectiveness of the partnership. 


\section{References}

Barr, H., Koppel, I., Reeves, S., Hammick, M., \& Freeth, D. S. (2008). Effective interprofessional education: Argument, assumption and evidence (promoting partnership for health). Hoboken, NJ: John Wiley \& Sons.

Centers for Disease Control and Prevention. (2012). Parent engagement: Strategies for involving parents in school health. Atlanta, GA: U.S. Department of Health and Human Services. Retrieved from https://www.cdc.gov/healthyyouth/protective/pdf/parent_engagement_strategies.pdf

Checkoway, B . (2011) What is youth participation? Children and Youth Services Review, 33(2), 340-345.

Denman, S. (1999). Health promoting schools in England - A way forward in development. Journal of Public Health Medicine, 21(2), 215-220.

Didier, J., McNamara, P. M., Simar, C., Geary,T., \& Pommier, J. (2010). Factors influencing the contribution of staff to health education in schools. Health education research, 25(4), 519-530.

Dooris, M. (2006). Health promotion settings: Future direction. Promotion \& Education, 13, $2-4$.

Griebler, U., \& Nowak, P. (2012). Student councils: A tool for health promoting schools? Characteristics and effects. Health Education, 112, 105-132.

Griebler, U., Rojatz, D., Simovska, V., \& Forster, R. (2014). Effects of student participation in school health promotion: A systematic review. Health Promotion International, 9. https://doi. org/10.1093/heapro/dat090

Hamdan, S., Story, M., French, S. A., Fulkerson, J. A., \& Nelson, H. (2005). Perceptions of adolescents involved in promoting lower-fat foods in schools: Associations with level of involvement. Journal of the American Dietetic Association, 105, 247-251.

Jensen, B., \& Simovska V. (2005). Involving students in learning and health promotion processes-Clarifying why? what? and how? Promotion \& Education, 12(3-4),150-156.

Jourdan, D., Samdal ,O., Diagne, F., \& Carvalho, G. S. (2008). The future of health promotion in schools goes through the strengthening of teacher training at a global level. Promotion \& Education, 15, 36-38.

Larson, R. W., \& Angus, R. M. (2011). Adolescents' development of skills for agency in youth programs: Learning to think strategically. Child Development, 82, 277-294.

Potvin, L. (2007). Managing uncertainty through participation. In D. V. McQueen, I. S. Kickbusch, L. Potvin, J. Pelikan, L. Balbo, \& T. Abel (Eds.), Health and modernity: The role of theory in health promotion (pp. 103-128). New York: Springer.

Ramey, H. L., \& Rose-Krasno, L. (2015). The new mentality: Youth-adult partnerships in community mental health promotion. Children and Youth Services Review, 50, 28-37.

Shah, S. (2011). Pakistani diaspora in Britain: Intersections of multi-locationality and girls' education. British Journal of Sociology of Education, 32(5), 763-783.

Simovska, V. (2007). The changing meanings of participation in school-based health education and health promotion: The participants' voices. Health Education Research, 22(6), 864-878.

Tucker, S., Lanningham-Foster, L., Murphy, J., Olsen G., Orth K., Voss J., ... Lohse, C. (2011). A school based community partnership for promoting healthy habits for life. Journal of Community Health, 36(3), 414-422. 
Victorian Health Promotion Foundation. (2008). The partnerships analysis tool. Retrieved from https://www.vichealth.vic.gov.au/ /media/resourcecentre/publicationsandresources/general/ vhp\%20part\%20toollow\%20res.ashx

Victorian Health Promotion Foundation. (2011). The partnerships analysis tool. Victorian Health Promotion Foundation, Melbourne, Australia.

Whole Child Education. (2009). Principles of effecctive partnership. Retrieved from www. wholechildeducation.org/assets/content/mx-resources/handoutprinciplespartnership.pdf

World Health Organization. (1986). Ottawa charter for health promotion. Copenhagen, Denmark: Author.

Young, I., Buijs, G., \& Jociute, A. (2014, December). Effective networks and partnerships for health promotion in schools. Retrieved from http://www.schools-for-health.eu/uploads/files/ SHE-Factsheet3-LR.pdf 